\title{
Determining the Dependence of Deformation during Diffusion Welding on the Aspect Ratio Using Samples Made of SS 304 (1.4301)
}

Thomas Gietzelt*, Volker Toth, Andreas Huell, Roland Dittmeyer

Karlsruhe Institute of Technology, Institute for Micro Process Engineering

Hermann-v.-Helmholtz-Pl. 1, 76344 Eggenstein-Leopoldshafen, Germany

E-mail: thomas.gietzelt@kit.edu

\begin{abstract}
In case of uniaxial diffusion welding, deformation depends not only on the level of temperature, bearing pressure, and time, but also on the aspect ratio and the absolute height. The reason is that deformation is inhibited by friction between the sample and the stamp applying the load due to different thermal expansion coefficients.

The number of surfaces to be leveled during the welding process affects the value of deformation, too. Hence, deformation of multilayered parts will be higher than that of parts consisting of two halves only.
\end{abstract}

In this paper, samples of different diameters and heights made of SS 304 are investigated at a temperature of $1075^{\circ} \mathrm{C}$, a bearing pressure of $25 \mathrm{MPa}$, and a bonding time of $\mathrm{t}=4 \mathrm{~h}$. These values were chosen based on the experience gained from previous work and to achieve reasonable deformation at large diameters and for flat samples as well. From the results, a regression was derived to calculate the expected deformation depending on the sample diameter and the aspect ratio, respectively. The approach was verified by experiments with the same welding parameters at arbitrary diameters and heights.

To distinguish the influence of the number of layers, stacks made of sheet material of variable diameters and heights were diffusion-welded, too. 
Keywords: Diffusion welding, diffusion joining, diffusion bonding, SS304, dependence of deformation

\section{Introduction}

Diffusion welding is used by a number of companies in industry for special joining applications. Especially in the aerospace sector, parts for applications involving large-sized sheet material or complex geometries are diffusion-bonded, e.g. for manufacturing sections with integrated reinforcing structures or vessels. ${ }^{[1,2]}$

Diffusion welding is a solid-state welding technique, where the whole part is subjected to pressure for a long time at elevated temperature. No heat-affected zone (HAZ) occurs, but the whole part is subjected to a heat treatment. Strengthening effects by cold working or precipitation hardening using supersaturated mixed crystals are lost. Instead, a soft-annealed condition appears, since the cooling rate is mostly rather low. The big advantage of diffusion welding, however, is that holohedral internal cross sections can be welded. Mostly, diffusion welding is carried out under high vacuum. This is the reason for low heating and cooling rates below temperatures at which energy transfer shifts from radiation to convection.

The welding process proper can be divided into several phases, such as approaching surfaces at atomic level, diffusion across different layers, and closing of remaining pores. In general, diffusion is determined by the temperature and dwell time. The applied bearing pressure, however, is responsible for the initial approach of surfaces by the deformation of asperities. Afterwards, the bearing pressure determines deformation. Since deformation is supposed to be limited for most applications, the bearing pressure should be set to an appropriate level. 
If the process is controlled perfectly for a material or application, no joining plane can be found afterwards and the mechanical properties correspond to the properties of the bulk material. ${ }^{[3,4]}$

The need of a certain deformation for diffusion welding to achieve good joining is the main disadvantage: For each material and each constructional design, the parameters of temperature, bearing pressure, and dwell time must be optimized. Layers containing microstructures exhibit irregular deformation behaviors over the height. Even for different percentaged cross sections, deformation varies at the same bearing pressure. In thin-walled internal microstructures, deformation may be influenced by grain boundary sliding. Narrow walls consisting of a few grains only may deform more easily.

In multiple layers, problems may be caused by pressure transfer across the height. Design engineering with trapezoidal cross sections of thin walls may counteract and limit deformation.

Furthermore, deformation is influenced by geometric properties, such as the aspect ratio: The reason is friction between the stamp applying the pressure to the part and the different coefficients of thermal expansion of the stamp material and the part. For stability reasons at high temperatures, the stamps are often made of TZM, a precipitation-hardened molybdenum alloy. Since the coefficient of thermal expansion follows Grüneisen's rule, implying a linear thermal expansion of about $2 \%$ up to the melting temperature, high-melting alloys possess a low coefficient of thermal expansion. ${ }^{[5]}$

Recently, an increased demand for diffusion welding of stainless steels by industry can be stated, expanding diffusion welding to new applications.

In this paper, deformation results of systematic diffusion welding experiments using austenitic stainless steel SS304 samples of various diameters and aspect ratios are reported. For one set of experiments, samples consisting of two pieces of the same height were used. 
As shown elsewhere, the deformation of multiple layered parts can differ for the same height due to leveling of multiple surface roughnesses. ${ }^{[6]}$ This gives rise to the questions of whether multiple interfaces and friction between them influence the deformation shape compared to parts consisting of two pieces only. Hence, diffusion welding experiments were performed for two diameters using samples made of multiple sheets and deformation results were compared to the deformation of samples consisting of two pieces only.

Austenitic stainless steels exhibit no phase transformation versus temperature and their diffusion coefficient decreases by two orders of magnitude after phase transition (Figure 1). This impedes the formation of a monolithic part and diffusion welding always is accompanied by irreversible grain growth. Hence, for austenitic stainless steels completely different parameters for diffusion bonding are necessary compared to mild steel.

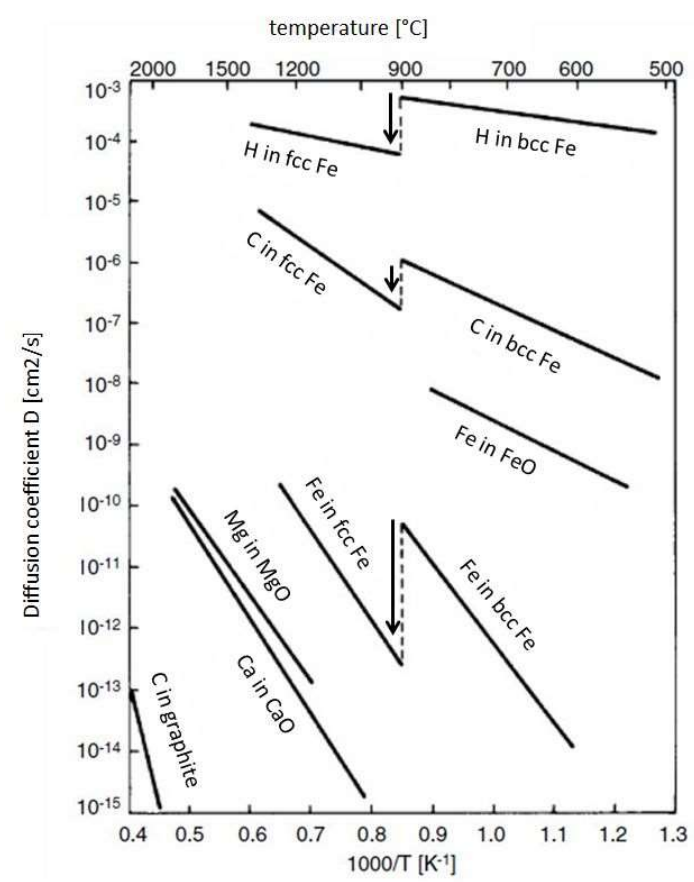

Figure 1: Change of the diffusion coefficient of iron and other elements as a function of the type of lattice versus temperature $(\mathrm{fcc}=$ face-centered cubic; $\mathrm{bcc}=$ body-centered cubic $)$. Adapted from ${ }^{[7]}$. 


\section{Experimental Procedure}

\subsection{Sample Geometry}

Samples were made of round stock of 1.4301 of $20,40,80$, and $160 \mathrm{~mm}$ in diameter, respectively. Two halves, each of 5, 10, 20, 30, 50, and $75 \mathrm{~mm}$ in height, respectively, were turned to obtain a maximum aspect ratio of two. An overview of the samples with aspect ratios can be found in Table 1 .

For samples made of multiple sheet material, disks with a thickness of $1 \mathrm{~mm}$ were cut by means of a laser.

All samples were diffusion-welded at $\mathrm{T}=1075^{\circ} \mathrm{C}, \mathrm{t}=4 \mathrm{~h}$, and $\mathrm{p}=25 \mathrm{MPa}$. These values were chosen to achieve a reasonable high deformation for thin samples of large diameters and to limit the error of measurement. From Figure 2, formation of a monolithic part by grain growth across the bonding plane is obvious.

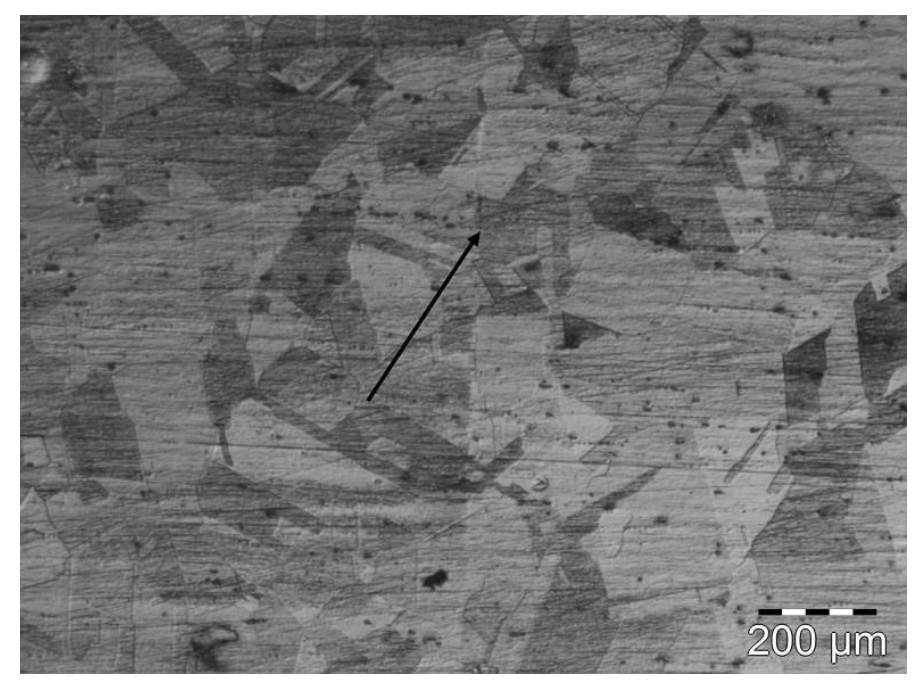

Figure 2: $\quad$ Metallographic cross section of SS304 (1.4301) diffusion-welded at $\mathrm{T}=1075^{\circ} \mathrm{C}, \mathrm{t}=4 \mathrm{~h}, \mathrm{p}=25 \mathrm{MPa}$. The bonding plane is indicated by an arrow.

\subsection{Sample Preparation and Diffusion Welding}

Pieces of appropriate diameters and heights were turned using round stock. The flatness was measured at five spots of each part, at 3;6;9 and 12 o'clock related to a clock face, and in the middle. In most cases, a flatness of about $50 \mu \mathrm{m}$ could be achieved, see Table 1 . The variation 
of height depends on the diameter of the parts: For larger diameters, deviation increases. For large diameters and relatively thin disks of $5 \mathrm{~mm}$, cold work hardening may lead to a certain distortion, too.

Another question arising is which parameter should be compared: Samples of the same heights or of the same aspect ratios? It was agreed that certain heights are more helpful due to practical reasons: Mostly, samples have a certain height, but not a fixed aspect ratio. For high samples, consisting of multiple sheets, the leveling of multiple surface roughnesses additionally contributes to deformation and the latter cannot be compared to the deformation obtained for samples consisting of two pieces only.

The number of large-diameter samples was limited to save material. Only three samples of $160 \mathrm{~mm}$ in diameter were tested. To obtain deformation values for very flat samples, a height of $10 \mathrm{~mm}$ was set in addition to heights of 60 and $150 \mathrm{~mm}$ for comparison to other diameters. As a consequence, however, the maximum aspect ratio was less than one for $160-\mathrm{mm}$ samples.

Subsequently, all parts were cleaned in alcohol and acetone. For diffusion welding, two pieces of the same height were stacked on top of each other. The interfaces between samples and TZM stamps were coated using boron nitride spray to reduce friction and to prevent sticking. For the $160-\mathrm{mm}$ sample of $150 \mathrm{~mm}$ in height, additional tantalum sheets were used, since experience had shown that boron nitride is displaced and sticking occurs at high deformation. A reasonable deformation must also be achieved for thin samples in order to limit the error when comparing the deformations of different sample diameters and aspect ratios. Hence, a welding time of $4 \mathrm{~h}$ and a high bearing pressure of $25 \mathrm{MPa}$ were used for all experiments. After diffusion welding, the variation of thickness was measured again. Values are given in Table 1.

Since mechanical stabilities of diffusion welding furnaces vary and thermal distortion cannot be measured under hot conditions, the values for the flatness after diffusion welding vary 
considerably, especially for diameters of 80 and $160 \mathrm{~mm}$. At high values of deformation, especially for the high samples of $160 \mathrm{~mm}$ in diameter, the tantalum sheets for protecting the stamps from damage baked to the samples and had to be removed with force. This caused poor flatness and the errors relating to deformation, see Table 1.

To evaluate the influence of the error of flatness measurement on the deformation calculated after diffusion welding, the flatness value was related to percentage deformation of the samples: A high deviation of the flatness in combination with a low deformation during diffusion welding led to a high uncertainty of the results.

Table 1: $\quad$ Flatness of samples made of two pieces before and after diffusion welding experiments

\begin{tabular}{|c|c|c|c|c|c|c|}
\hline \multirow[t]{2}{*}{$\begin{array}{c}\text { Sample } \\
\text { (Ø and height) }\end{array}$} & \multirow[t]{2}{*}{$\begin{array}{l}\text { Aspect } \\
\text { ration }\end{array}$} & \multicolumn{2}{|c|}{$\begin{array}{l}\text { Deviation of } \\
\text { flatness before } \\
\text { diffusion } \\
\text { welding }[\mu \mathrm{m}]\end{array}$} & \multirow[t]{2}{*}{$\begin{array}{l}\text { Dev. of flatness } \\
\text { after diffusion } \\
\text { welding }[\mu \mathrm{m}]\end{array}$} & \multirow[t]{2}{*}{$\begin{array}{c}\text { Defor- } \\
\text { mation } \\
{[\%]}\end{array}$} & \multirow[t]{2}{*}{$\begin{array}{c}\text { Flatness related to } \\
\text { percentage sample } \\
\text { deformation [\%] }\end{array}$} \\
\hline & & Part 1 & Part 2 & & & \\
\hline $20 \mathrm{~mm} ; 10 \mathrm{~mm}$ & 0.5 & 5 & 8 & 8 & 18.54 & 0.44 \\
\hline $20 \mathrm{~mm} ; 20 \mathrm{~mm}$ & 1 & 13 & 20 & 19 & 28.91 & 0.33 \\
\hline $20 \mathrm{~mm} ; 40 \mathrm{~mm}$ & 2 & 1 & 2 & 51 & 31.07 & 0.41 \\
\hline $40 \mathrm{~mm} ; 10 \mathrm{~mm}$ & 0.25 & 10 & 49 & 34 & 14.19 & 2.38 \\
\hline $40 \mathrm{~mm} ; 20 \mathrm{~mm}$ & 0.5 & 13 & 11 & 22 & 20.44 & 0.53 \\
\hline $40 \mathrm{~mm} ; 40 \mathrm{~mm}$ & 1 & 4 & 1 & 11 & 22.78 & 0.12 \\
\hline $40 \mathrm{~mm} ; 60 \mathrm{~mm}$ & 1.5 & 61 & 29 & 11 & 27.84 & 0.07 \\
\hline $40 \mathrm{~mm} ; 100 \mathrm{~mm}$ & 2.5 & 9 & 5 & 50 & 28.37 & 0.18 \\
\hline $80 \mathrm{~mm} ; 10 \mathrm{~mm}$ & 0.125 & 23 & 39 & 84 & 9.64 & 8.55 \\
\hline $80 \mathrm{~mm} ; 10 \mathrm{~mm} \mathrm{~W}$ & 0.125 & 28 & 35 & 103 & 11.23 & 9.02 \\
\hline $80 \mathrm{~mm} ; 60 \mathrm{~mm}$ & 0.75 & 49 & 40 & 71 & 23.01 & 0.51 \\
\hline $80 \mathrm{~mm} ; 60 \mathrm{~mm} \mathrm{~W}$ & 0.75 & 29 & 40 & 139 & 22.25 & 1.04 \\
\hline $80 \mathrm{~mm} ; 100 \mathrm{~mm}$ & 1.25 & 38 & 31 & 98 & 23.62 & 0.41 \\
\hline $80 \mathrm{~mm} ; 150 \mathrm{~mm}$ & 1.875 & 55 & 20 & 323 & 25.59 & 0.84 \\
\hline $160 \mathrm{~mm} ; 10 \mathrm{~mm}$ & 0.0625 & 23 & 17 & 114 & 10.02 & 11.06 \\
\hline $160 \mathrm{~mm} ; 60 \mathrm{~mm}$ & 0.375 & 24 & 26 & 297 & 27.35 & 1.81 \\
\hline $160 \mathrm{~mm} ; 150 \mathrm{~mm}$ & 0.9375 & 18 & 10 & 460 & 33.66 & 0.91 \\
\hline
\end{tabular}




\subsection{Diffusion Welding Furnaces and Welding Procedure}

Depending on the diameter and the force applied for samples of different diameters, three different diffusion welding furnaces were used: Furnace I with a maximum load of $20 \mathrm{kN}$ was used for samples of $20 \mathrm{~mm}$ in diameter. For diameters of 40 and $80 \mathrm{~mm}$, respectively, furnace II with a maximum load of $200 \mathrm{KN}$ was used. Furnace III with a maximum load of $2 \mathrm{MN}$ was used for the 160-mm samples (Figure 3). Furnaces I and II were made by MAYTEC for temperatures up to $1400^{\circ} \mathrm{C}$. Furnace III was made by SYSTECH with a maximum temperature of $1300^{\circ} \mathrm{C}$.

Each furnace is equipped with a two-step vacuum system combining a rotary vane and a turbopump to achieve high vacuum in the range of $10^{-5} \mathrm{~Pa}$. Metallic heaters made of molybdenum heat the sample by IR radiation. The vessel is water-cooled to protect the door sealing and shielded by tungsten sheets to reduce heat flow.

The only difference concerning the use of the different furnaces is the heat transfer by radiation from the metallic heaters to the samples and the sample mass. For this, an appropriate dwell time is specified according to the sample geometry and mass.

All furnaces are equipped with thermocouples of type S (Pt10\%Rh-Pt), class 1, with an accuracy of $\pm 1.0 \mathrm{~K}$ or $\pm[1+0.003(\mathrm{t}-1100)] \mathrm{K}$ between $0-1600^{\circ} \mathrm{C}$. They are attached to the samples by the operator. Since the furnaces start heating under vacuum only, aging of thermocouples should not be an issue. This shows that the derived values for Eq. 2 to calculate deformations for arbitrary sample diameters and aspect works well. 

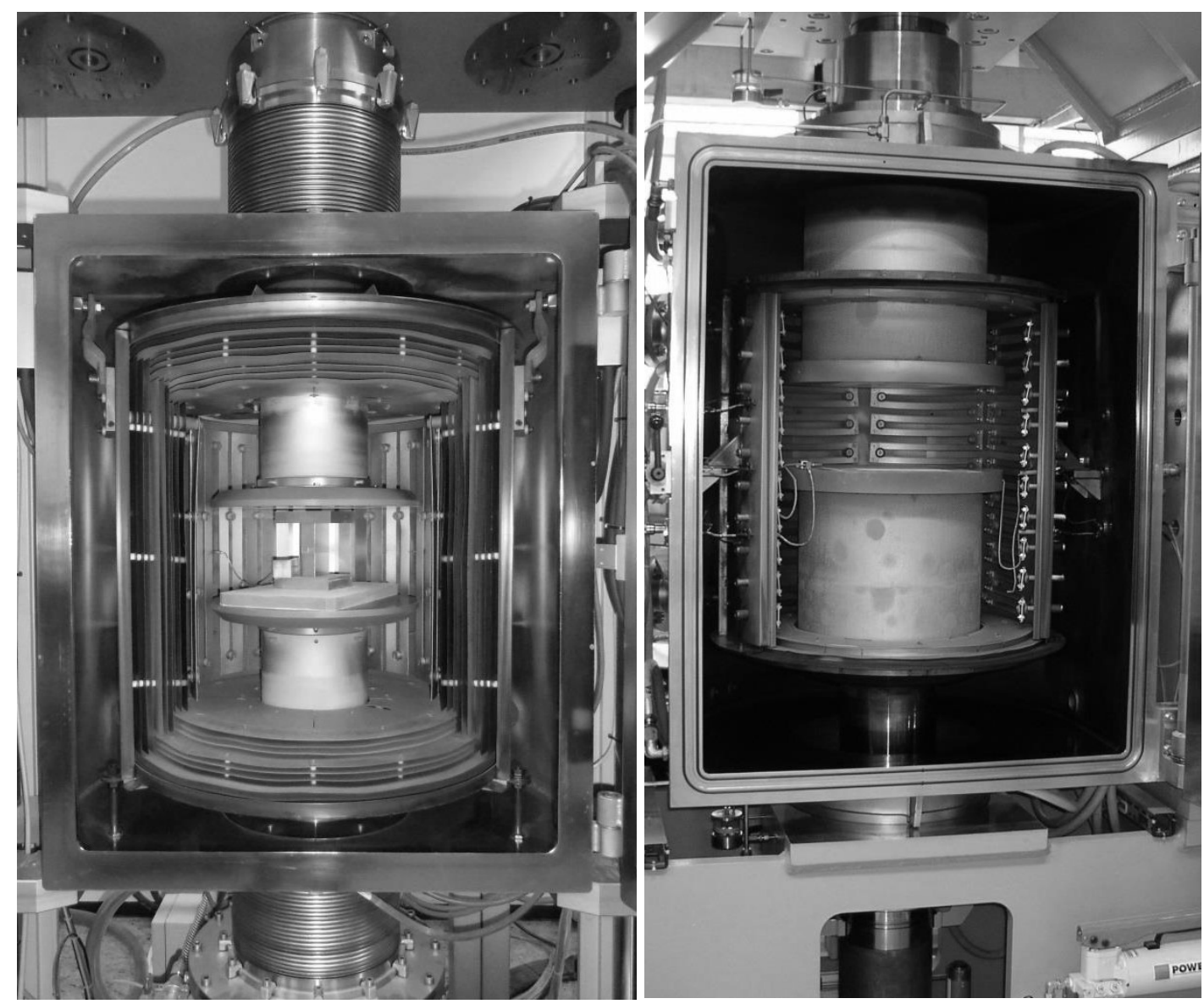

Figure 3: Diffusion welding furnaces II (left, max. force $200 \mathrm{kN}$, stamp diameter $200 \mathrm{~mm}$ ) and III (right, max. force $2 \mathrm{MN}$, stamp diameter $500 \mathrm{~mm}$ ).

After inserting the sample, a preload of $0.5 \mathrm{kN}$ was applied to set the zero point in terms of stamp position and the welding experiment was started. When a vacuum threshold of $1 * 10^{-5}$ mbar was exceeded, heating was started until the temperature of the set point was reached. In case the vacuum dropped due to degassing, heating was stopped automatically at a threshold of $8^{*} 10^{4}$ mbar and proceeded at a threshold of $6^{*} 10^{-4}$ mbar. If the vacuum decreased below $1 * 10^{-3}$ mbar, however, the experiment was stopped by the software. The heating rate was limited to $10 \mathrm{~K} / \mathrm{min}$ due to thermal stress. After an initial dwell time, the full load was applied and welding started for the indicated bonding time. The cooling rate was limited to $15 \mathrm{~K} / \mathrm{min}$. However, intrinsic cooling in vacuum was lower from about $850^{\circ} \mathrm{C}$, due to the weight of the equipment. The vacuum was maintained until a temperature of $200^{\circ} \mathrm{C}$ was reached in order to protect the metallic heaters and heat shields from oxidation. 


\section{Results}

As mentioned in section 2.3, samples of different diameters were welded in different furnaces. From Eq. 1, it is obvious that the temperature has a strong impact on deformation. Actually, the diffusion coefficient nearly doubles in the temperature range of $20 \mathrm{~K}$ used for diffusion welding. Use of different furnaces may result in a certain deviation of temperatures, and deformation may be affected.

Eq. 1

$$
D=D_{0} * \exp \left(\frac{-\Delta U}{R T}\right)
$$

\subsection{Deformation Behavior of Samples Made of Two Pieces}

Table 1 summarizes the deformations resulting from diffusion welding of samples with different diameters and aspect ratios, respectively. Diffusion welding of selected samples of $80 \mathrm{~mm}$ in diameter was repeated for proof reasons.

For practicability reasons, there are some uncertainties. Not the whole field of parameters in terms of diameter and height can be covered by experiments: For example, samples of only $20 \mathrm{~mm}$ in diameter and an aspect ratio above two cannot be welded without housing, since they tend to shift (Figure 4 a)).
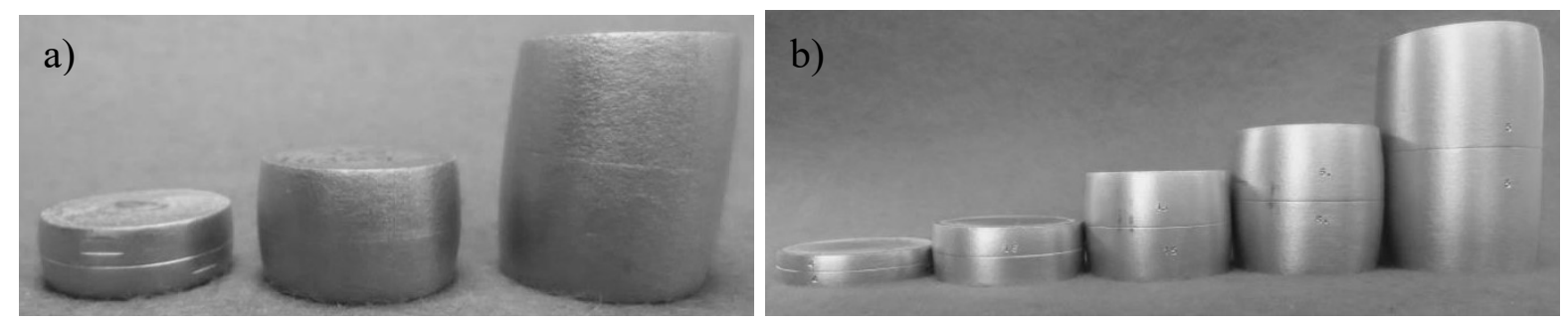

Figure 4: a) Diffusion welding samples $\varnothing=20 \mathrm{~mm}, \mathrm{~h}=10 ; 20 ; 40 \mathrm{~mm}$ and b) $\varnothing=40 \mathrm{~mm}, \mathrm{~h}=10 ; 20 ; 40 ; 60 ; 100 \mathrm{~mm}$.

For the samples of $10 \mathrm{~mm}$ in height, deformation ranged from $18.5 \%$ for a diameter of $20 \mathrm{~mm}$ to $10 \%$ for a diameter of $160 \mathrm{~mm}$. This means that for thin samples the deformation decreases by $46 \%$ depending on the diameter, illustrating the strong impact of friction. 
Furthermore, it can be stated that the deformation increases over the whole range of aspect ratios and is more than doubled.

For a diameter of $40 \mathrm{~mm}$, deformation is nearly the same for heights of 20 and $40 \mathrm{~mm}$. For heights of 60 and $100 \mathrm{~mm}$, deformation increases by more than $5 \%$, but is similar for both heights again (Figure 4 b)).

For a sample diameter of $80 \mathrm{~mm}$, deformation is doubled when the height increases from $10 \mathrm{~mm}$ to $60 \mathrm{~mm}$. However, for heights of 60,100 , and $150 \mathrm{~mm}$, only a very slight increase of deformation occurs. This is in contradiction to the diameter of $160 \mathrm{~mm}$ : Here, a clear increase of deformation is visible.

Comparison of deformation for a constant sample height of $60 \mathrm{~mm}$ revealed that it was in the range of 22.2 to $27.8 \%$ for samples of 40,80 , and $160 \mathrm{~mm}$ in diameter. On the one hand, the impact of the height on deformation seems to decrease. On the other hand, deformation obtained for 80 -mm diameter samples obviously is smaller than for samples of 40 and $160 \mathrm{~mm}$ in diameter. Since samples of 40 and $80 \mathrm{~mm}$ in diameter were welded in furnace II and samples of $160 \mathrm{~mm}$ in diameter in furnace III, the offset could be attributed to the different equipment.

For all deformation data obtained, a nonlinear fit (see Eq. 2) describing the deformation to be expected for arbitrary diameters and heights was derived using ORIGIN V9.0. The fit values are given below Eq. 2 .

Eq. $2 \quad \mathrm{Z}=\mathrm{z}_{0}+\mathrm{a} * \mathrm{x}+\mathrm{b} * \mathrm{y}+\mathrm{c} * \mathrm{x}^{2}+\mathrm{f} * \mathrm{x} * \mathrm{y}$

$\begin{array}{llll}\text { x } & \text { diameter }[\mathrm{mm}] & & \\ \text { y } & \text { height }[\mathrm{mm}] & & \\ & & \text { Value } & \text { Standard deviati } \\ \text { z0 } & \text { absolute term } & 26.03472 & 2.17402 \\ \text { a } & \text { linear coefficient for the diameter } & -0.37633 & 0.05625 \\ \text { b } & \text { linear coefficient for the height } & 0.29819 & 0.04736 \\ \text { C } & \text { quadratic coefficient for the diameter } & 0.0016 & 3.16487^{*} 10^{-4} \\ \mathbf{f} & \text { interaction coefficient of diameter and height } & 8.16084^{*} 10^{-4} & 3.20026^{*} 10^{-4} \\ \mathbf{R}^{\mathbf{2}} & \text { regression coefficient } & 0.89865 & \end{array}$


The deformations obtained are plotted for different diameters versus the aspect ratios in Figure 5. For this, repeated experiments for $\mathrm{d}=80-\mathrm{mm}$ samples were averaged. It can be seen that the correlation coefficient for the samples of $20 \mathrm{~mm}$ in diameter is poor, although only three different aspect ratios were welded due to the distortion already depicted in Figure 4. For diameters of 40 and $80 \mathrm{~mm}$, however, the correlation coefficient is better, although samples with four different aspect ratios were welded. Especially for the diameter of $40 \mathrm{~mm}$, the deformation seems to reach saturation for an aspect ratio of 2.5.

The large deformation of the samples of $160 \mathrm{~mm}$ in diameter in spite of their small aspect ratios and their highest impact of friction on the stamps is conspicuous.

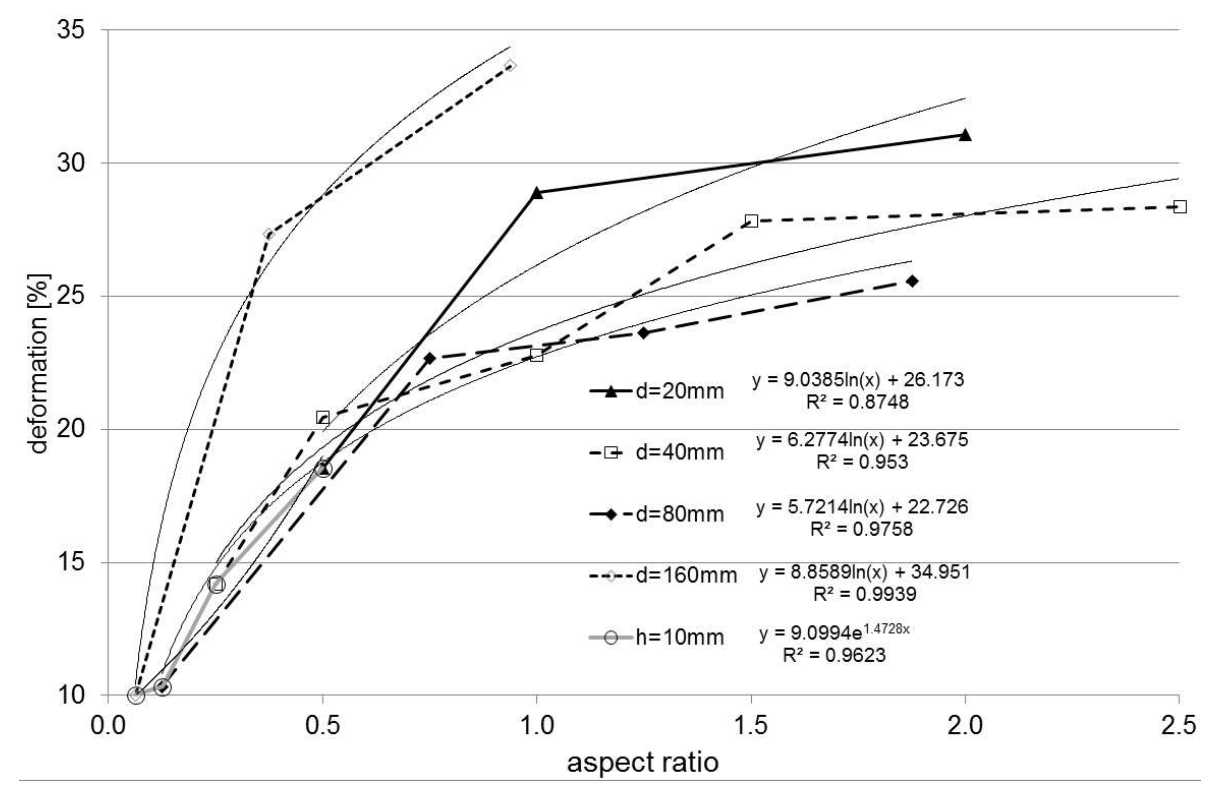

Figure 5: Plot of deformation versus aspect ratio for different sample diameters as well as for all samples $10 \mathrm{~mm}$ in height.

Also the deformations of all samples of $10 \mathrm{~mm}$ in height were plotted versus the aspect ratios in Figure 5 to illustrate the impact of friction for flat samples. Small diameters lead to higher deformation, whereas a limitation of the deformation seems to be reached around $10 \%$ for the given welding parameter, independently of the cross section. For an infinitesimally small aspect ratio, a boundary value of $9 \%$ deformation seems to be reasonable. 
In opposite to different diameters where a logarithmic trend fits deformation best, for $\mathrm{h}=10 \mathrm{~mm}$ an exponential fit shows the best coefficient of determination.

Table 2 gives an overview of diameter variations of the samples depending on their heights. The first and the last values represent the bottom and the top diameters, respectively. From both ends, the diameter was measured in distance steps of $10 \mathrm{~mm}$. In addition, the diameter at the bonding plane was measured, regardless of the distance of the diameter measured before (bold values in Table 2). It can be seen that the maximum diameter of the samples (italic values) does not always correspond to the bonding plane, although deviations are small.

Table 2: Diameters of the samples after diffusion welding measured at a distance of $10 \mathrm{~mm}$ from both ends and at the bonding plane

\begin{tabular}{|c|c|c|c|c|c|c|c|c|c|c|c|c|c|}
\hline $\begin{array}{l}\text { Sample } \downarrow \\
\text { (Ø and h) }\end{array}$ & $\begin{array}{c}\text { Point } \\
1\end{array}$ & $\begin{array}{c}\text { Point } \\
2\end{array}$ & $\begin{array}{c}\text { Point } \\
3\end{array}$ & $\begin{array}{c}\text { Point } \\
4\end{array}$ & $\begin{array}{c}\text { Point } \\
5\end{array}$ & $\begin{array}{c}\text { Point } \\
6\end{array}$ & $\begin{array}{c}\text { Point } \\
7\end{array}$ & $\begin{array}{c}\text { Point } \\
8\end{array}$ & $\begin{array}{c}\text { Point } \\
9\end{array}$ & $\begin{array}{c}\text { Point } \\
10\end{array}$ & $\begin{array}{c}\text { Point } \\
11\end{array}$ & $\begin{array}{c}\text { Point } \\
12\end{array}$ & $\begin{array}{c}\text { Point } \\
13\end{array}$ \\
\hline $20 / 10$ & 21.89 & 22.44 & 21.58 & & & & & & & & & & \\
\hline $20 / 20$ & 22.91 & 24.24 & 22.81 & & & & & & & & & & \\
\hline $20 / 40$ & 21.85 & 24.51 & 24.64 & 24.5 & 23.21 & & & & & & & & \\
\hline $40 / 10$ & 43.28 & 43.36 & 43.23 & & & & & & & & & & \\
\hline $40 / 20$ & 44.61 & 45,07 & 44.57 & & & & & & & & & & \\
\hline $40 / 40$ & 44,04 & 46.00 & 46.31 & 45.96 & 44.60 & & & & & & & & \\
\hline $40 / 60$ & 45.01 & 47.96 & 48.23 & 47.49 & 44.85 & & & & & & & & \\
\hline $40 / 100$ & 44.74 & 46.97 & 47.63 & 47.75 & 47.86 & 47.94 & 47.93 & 47.56 & 44.60 & & & & \\
\hline $80 / 10$ & 84.37 & 84.58 & 84.34 & & & & & & & & & & \\
\hline $80 / 10 \mathrm{~W}$ & 85.29 & 85.48 & 85.23 & & & & & & & & & & \\
\hline $80 / 60$ & 89.85 & 91.10 & 92.75 & 92.95 & 92.35 & 90.95 & 90.45 & & & & & & \\
\hline $80 / 60 W$ & 88.96 & 91.20 & 92.00 & 92.20 & 92.10 & 91.40 & 89.32 & & & & & & \\
\hline $80 / 100$ & 89.72 & 92.35 & 93.35 & 93.90 & 93.80 & 93.30 & 89.70 & 89.95 & 87.75 & & & & \\
\hline $80 / 150$ & 88.44 & 92.00 & 93.85 & 95.00 & 95.40 & 95.40 & 95.50 & 95.45 & 95.20 & 94.90 & 93.70 & 91.20 & 87.42 \\
\hline $160 / 10$ & 169,4 & 169.8 & 169.7 & & & & & & & & & & \\
\hline $160 / 60$ & 188.1 & 190.1 & 191.0 & 189.9 & 187.3 & & & & & & & & \\
\hline $160 / 150$ & 192.5 & 189.6 & 202.0 & 204.4 & 204.5 & 204.1 & 201.8 & 198.2 & 193.4 & 189.6 & 182.6 & & \\
\hline
\end{tabular}


For the sample of $\mathrm{d}=80 \mathrm{~mm}$ with a height of $150 \mathrm{~mm}$, the diameter increase can be described by a logarithmic equation fitting the profile very well (Figure 6).

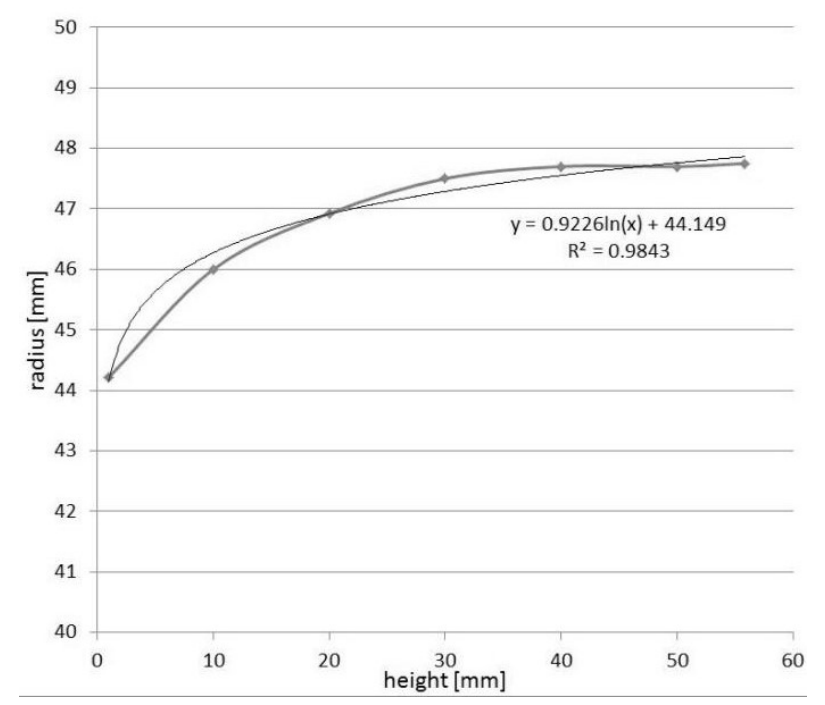

Figure 6: Fit of the diameter of sample $\mathrm{d}=80 \mathrm{~mm}, \mathrm{~h}=150 \mathrm{~mm}$.

From the values obtained, it was tried to derive a dependency for deformation on diameters and heights. As a rule of thumb, the diameter increases between $13(\mathrm{~d}=40 \mathrm{~mm}, \mathrm{~h}=20 \mathrm{~mm})$ and $20 \%$ at the maximum. For flat samples of only $10 \mathrm{~mm}$ in height, the increase is smaller, as has been expected. However, deformation does not decrease continuously with increasing diameter. An exception is observed for samples of $160 \mathrm{~mm}$ in diameter: This may be attributed to the different equipment used.

For $\mathrm{d}=20 \mathrm{~mm}$ and heights of 20 and $40 \mathrm{~mm}$ as well as for $\mathrm{d}=160 \mathrm{~mm}$ and $\mathrm{h}=150 \mathrm{~mm}$, however, the maximum diameter increased by more than $20 \%$. This trend could not be observed for samples of 40 and $80 \mathrm{~mm}$ in diameter, although the aspect ratio is more than 1 , too.

\subsection{Deformation Behavior of Samples Made of $1 \mathrm{~mm}$ Sheet Material}

For samples of 20 and $40 \mathrm{~mm}$ in diameter, diffusion welding experiments were performed to prove that higher deformation is caused by the leveling of multiple surface roughness. Figure 
7 illustrates the difference of samples made of two halves or layers of $1 \mathrm{~mm}$ thickness for $\mathrm{d}=40 \mathrm{~mm}$ for three different sample heights.
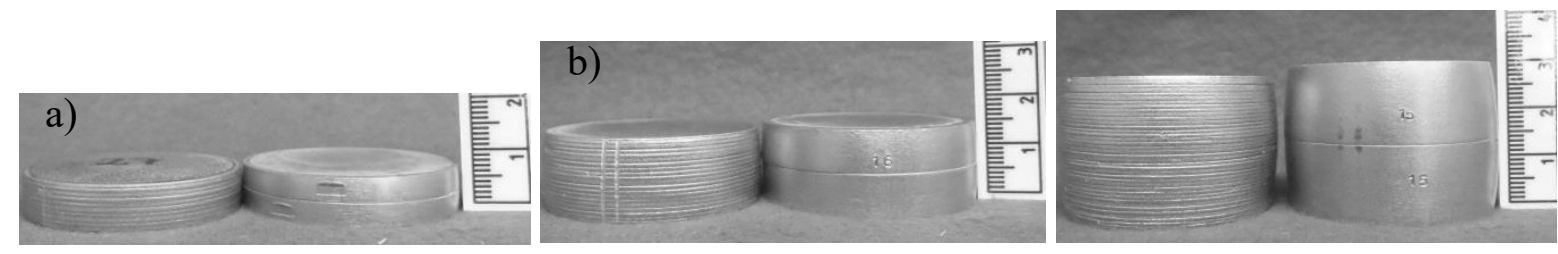

Figure 7: Comparison of diffusion-welded samples $\varnothing=40 \mathrm{~mm}, \mathrm{~h}=10$ (a); 20 (b) and $40 \mathrm{~mm}$ (c), made of two parts or of layers of $1 \mathrm{~mm}$ thickness.

Table 3 shows the deformation obtained for layered samples. It has to be mentioned that the sample of $\mathrm{d}=20 \mathrm{~mm}, \mathrm{~h}=40 \mathrm{~mm}$ showed a distortion similar to that in Figure 4 a) due to stability reasons. Hence, the deformation value must be considered with reservations. Compared to the values of samples made of two pieces only, which are listed in Table 1, deformation of layered stacks is considerably larger. Due to the distortion of the samples of $20 \mathrm{~mm}$ in diameter, there is no obvious trend. For the $40-\mathrm{mm}$ samples, however, it can be concluded that the additional deformation corresponds to roughly $0.1 \%$ per layer. It is attributed to the levelling of additional surface roughness.

Table 3: Deformations obtained from diffusion welding experiments for samples made of $1 \mathrm{~mm}$ sheet material

\begin{tabular}{|c|c|c|c|c|}
\hline $\begin{array}{c}\boldsymbol{\sigma}[\mathrm{mm}] \rightarrow \\
\mathbf{h}[\mathrm{mm}] \downarrow\end{array}$ & \multicolumn{3}{|c|}{20} & \multicolumn{2}{|c|}{} \\
\hline & $\begin{array}{c}\text { Deformation } \\
{[\%]}\end{array}$ & $\begin{array}{c}\text { Increase of deformation } \\
\text { compared to samples } \\
\text { made of two pieces [\%] }\end{array}$ & $\begin{array}{c}\text { Deformation } \\
{[\%]}\end{array}$ & $\begin{array}{c}\text { Increase of deformation } \\
\text { compared to samples } \\
\text { made of two pieces [\%] }\end{array}$ \\
\hline 10 & 21.87 & 3.33 & 15.17 & 0.98 \\
\hline 20 & 30.91 & 2.00 & 22.1 & 1.66 \\
\hline 40 & 37.5 & 6.43 & 26.45 & 3.67 \\
\hline
\end{tabular}

The diameters at the bonding plane were compared for samples made of two pieces and of $1 \mathrm{~mm}$ sheet material. No obvious trend could be found that additionally sliding planes for layered samples promote deformation to larger diameters. Only for $\mathrm{d}=40 \mathrm{~mm}, \mathrm{~h}=40 \mathrm{~mm}$, the 
diameter of the layered sample was larger than for the sample made of two pieces. There is also no obvious trend for diameters at the top and bottom of samples made of two pieces and sheet material. Probably, the layered stacks help to reduce the transmission of friction between sample and TZM stamp into the part, thus allowing a larger deformation of the sample at the interfaces. Samples made of sheet material tend to have a less pronounced barrel-shaped outline than compact samples.

\subsection{Diffusion Welding of Samples of Arbitrary Diameters and Heights}

The derived values for Eq. 2 were used to calculate the expected deformation of two samples with arbitrary diameter and height, respectively. For $\mathrm{d}=50 \mathrm{~mm}, \mathrm{~h}=30 \mathrm{~mm}$ a deformation of $21.4 \%$ was predicted. The experiment led to $20.9 \%$. For $\mathrm{d}=30 \mathrm{~mm}, \mathrm{~h}=50 \mathrm{~mm}$ a deformation of $32.3 \%$ was calculated whereas the experiment showed a deformation of $31.3 \%$.

According to maximum forces of furnaces, the first sample with $\mathrm{d}=50 \mathrm{~mm}$ was welded in

furnace II, whereas the second sample with $d=30 \mathrm{~mm}$ was welded in furnace I. In spite of the different equipment, the deviation between real and calculated deformations is less than $1 \%$. In relative numbers, the calculated values differ by 2.4 and $2.9 \%$, from practical experiments, respectively. From this, it can be seen that the regression works very well in spite of the uncertainties arising from the different furnace setups.

\section{Discussion and Outlook}

The experiments presented in this paper refer to austenitic stainless steels with $18 \%$ chromium and $8 \%$ nickel, exhibiting no phase transformation with temperature. The austenitic structure exhibits a diffusion coefficient of about 1/100 compared to ferritic steels. The passivation layer that is responsible for good corrosion resistance and insoluble in the matrix material decreases diffusion across bonding planes. These issues make diffusion welding much more complicated than for mild steel. ${ }^{[8]}$ 
Other stainless steels with different contents of chromium, nickel, and additional alloying elements, e. g. for heat-resistant alloys, may exhibit a passivation layer of even higher stability which prevents successful diffusion welding at $1075^{\circ} \mathrm{C}$. Possibly higher joining temperatures help to overcome thermal stability of these passivation layers. In this paper, barrel-shaped deformation of samples of $10 \mathrm{~mm}$ in height is low and strongly depends on the cross section to be welded. Especially for thin samples with a large cross section, the diffusion welding process should be optimized for low deformation. When doing so, however, the absolute deformation in micrometers will often be in the range of the flatness. This makes it difficult to reproduce a certain deformation and the calculation error will be high. If multiple consecutive internal microstructures are present e.g. for mixing, it may be difficult to specify a constant pressure loss. Appropriate design-engineering work may help to limit the influence of deformation on the hydraulic diameter. In general, deformation depends on heights and aspect ratios of the samples and distortion of the outline increases with height. These are reasons why it is difficult to predict the deformation of a real part even at fixed parameters of bonding temperature, dwell time, and bearing pressure. Furthermore, deformation is influenced by the number of layers to be welded and internal structures due to levelling of multiple surfaces. Especially the impact of internal mechanical microstructures on the distortion along the height should be investigated in more detail.

In the experiments presented, a set of parameters was used to obtain reasonable deformations also for flat samples and to limit the error of measurement. For real parts, however, deformation is limited to much smaller values. A sufficient oversize should be considered e. g. for subsequent machining to be able to fit the parts into housings. Another issue for diffusion welding is to specify a deformation necessary to achieve a high vacuum tightness at least: It always depends also on the number of layers to be welded. 
The result is also influenced by the equipment: The stability or thermal distortions of the furnace at high temperatures influence the parallel misalignment of the stamps and are hard to evaluate under hot conditions.

Attention must be paid measuring the temperature; since the diffusion coefficient of metals doubles in the temperature range in question within approximately $20 \mathrm{~K}$. Depending on the quality of the vacuum inside the furnace and the way how thermocouples are attached to the samples aging might be an issue. Hence, thermocouples should be calibrated from time to time, if diffusion welding is not performed under high vacuum or inert gas of a purity of 5.0 or better. Different layouts of furnaces and heat shielding may influence the transfer of heat to the parts and heat loss. Diffusion bonding parameters like temperature, dwell time and bearing pressure optimized at a certain part will not result in the same value of deformation if transferred to other equipment, e.g. due to different thermal inertance, or to parts of different dimensions and weights. ${ }^{[9]}$ Dwell time must be adapted to heat through the parts depending on their size and weight.

It was shown that the derived correlation is suited well for predicting deformations for arbitrary diameters and heights of samples in spite of the fact that three different furnaces were used.

Due to the extreme variation of properties of different sorts of steel in terms of phase transformation, diffusion coefficient, and surface layers, comprehensive further research should be performed for each class of steels. Depending on alloying elements, the temperature level of the ferritic-austenitic phase transformation is shifted or even suppressed. Phase transformation, however, is a great possibility to achieve good diffusion welding results, since a completely new grain structure is formed and grain growth versus time at high temperatures does not apply, contrary to austenitic stainless steels in these experiments. 
Additionally, the 100-fold diffusion coefficient in the cubic body-centered lattice may be an advantage, leading to a completely different set of appropriate diffusion welding parameters. $[10,11]$

\section{Conclusion}

In general, diffusion welding parameters like bonding temperature, dwell time and bearing pressure must always be optimized individually for each design and material. This and long cycle times are the main obstacles for commercialization of diffusion welding. The quality of a joint made by diffusion bonding should be evaluated not only by vacuum tightness but also by grain growth across the bonding plane.

Depending on the design, deformation may vary, especially if mechanical microstructures in the dimension of the grain size are present. The deformation should be limited to the essential value for achieving a good bonding quality, and to prevent affecting functionality. Especially for steels, many different types of alloys exist, requiring completely different sets of bonding parameters to control deformation and to ensure good bonding results. For mild steels phase transformation with temperature from ferrite to austenite occur which is extremely helpful to form a monolithic compound.

Stainless steels however possess stable passivation layers impeding diffusion. The austenitic or ferritic microstructure can be stabilized, depending on the composition. Also the deformation behavior is completely different compared to mild steel.

For austenitic stainless steel always long dwell times are necessary to achieve grain growth across bonding layers, due to the low diffusion coefficient and stable passivation layers. Possibly, the resulting large grain size may be disadvantageous in terms of corrosion resistance or mechanical behavior for potential applications.

\section{Literature}


[1] L. D: Hefti, J. Mater Eng Perform, vol. 13, No. 6, 2004, pp. 678-682

[2] H.-S. Lee, J.-H. Yoon, J.-T. Yoo, AMM, Vol. 87, 2011, pp. 182-185

[3] M. W. Mahoney and C. C. Bampton: „Welding, Brazing and Soldering”, ASM Handbook, Vol. 6, ASM International, Materials Park, OH, 1995, pp. 156-59

[4] N. F. Kazakov: „A theory of diffusion bonding, Diffusion Bonding of Materials”, Mir Publisher, Moscow, 1985, ISBN 0-08-032550-5

[5] E. Hornbogen, „Werkstoffe - Aufbau und Eigenschaften“, 2nd Ed., Springer, Berlin, Heidelberg, New York 1979

[6] T. Gietzelt, V. Toth, A. Huell, F. Messerschmidt, R. Dittmeyer, Adv. Eng. Mater., Vol. 16, No. 11, 2014, pp. 1381-1390, DOI: 10.1002/adem.201400035

[7] G. Gottstein: „Materialwissenschaft und Werkstofftechnik“, 4th Ed., Springer Vieweg, Berlin Heidelberg, ISBN 978-3-642-36602-4, DOI 10.1007/978-3-642-36603-1, 2014, p. 173

[8] J. Wilden, J. P. Bergmann, S. Jahn, W. Beck, DVS 243, 2010, pp. 59-64

[9] S. Jahn, S. Sändig, S. Dahms, F. Gemse, Mat.-wiss. U. Werkstofftechnik, 2014, 45, No. 9, DOI 10.1002/mawe.201400285, p. 807-813

[10] D. R. Askeland: „The Science and Engineering of Materials”, Boston, Cengage Learning, 7th ed. ISBN 978-1-305-07676-1, 1989, p. 153

[11] T. Gietzelt, V. Toth, A. Hüll: „Diffusion Bonding: Influence of Process Parameters and Material Microstructure", accepted, InTECH open, 2016 